\title{
Para além do corpo moderno
}

Lilian do Vale ${ }^{1}$

Buscando ir além da crítica às representações do corpo predominantes na Modernidade, o presente artigo recorre ao Perí psychés, texto em que Aristóteles apresenta sua teoria da unidade do corpo e da alma, para sugerir a possibilidade de superação formal dessa dualidade; mas busca, em seguida, na verve foucaultiana os termos de uma reflexão sobre as tensões que marcam as experiências do corpo em um continuum que vai da negação à presença.

Palavras-chave: corpo moderno; unidade corpo e alma; hilemorfismo; corpo utópico.

\section{Beyond the modern body}

Aiming to go beyond criticism of the dominant representations of the body in Modernity, this article evokes the genius of the Perí psychés, in which Aristotle presents his theory of the unity of body and soul, to suggest the possibility of formally surpassing this duality; thereafter find in Foucaultian verve the terms of a reflection on the tensions that mark the experiences of the body, in a continuum that goes from negation to presence.

Key-words: modern body; unity of body and soul; hylomorphism; human compound ; utopic body

${ }^{1}$ Professora titular de Filosofia da Educação da UERJ, pesquisadora do CNPq, sua atuação e trabalhos concentram-se na área de reflexão sobre a formação humana e têm como principais interesses teóricos, na atualidade, a filosofia do corpo, o cosmopolitismo, a crítica ao cognitivismo. Autora, entre outros, de Enigmas da Educação (Autêntica), a Escola Imaginária (DPA) e A Escola e a Nação (Letras \& Letras). 


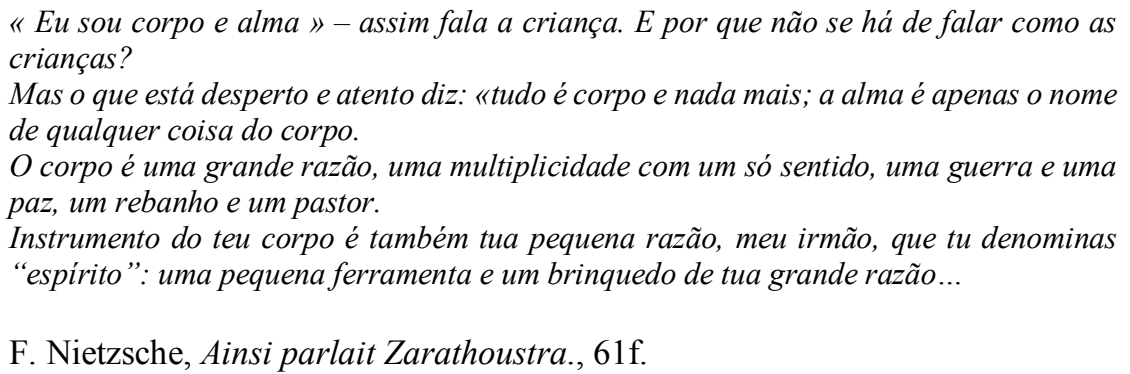

A única coisa que eu não posso evacuar pelo pensamento é o pensamento. Logo, eu sou - eu só posso ser - o que Descartes denomina uma «coisa que pensa», uma res cogitans, segundo minha natureza essencial. Posso, assim, facilmente pensar que não tenho corpo! (...) Eis, em poucas palavras, o argumento: eu não posso inteligivelmente duvidar de minha própria existência, uma vez que a dúvida é uma forma de pensamento e que, se penso, eu existo. Em contrapartida, posso inteligivelmente duvidar que tenha um corpo. Resulta dai que não sou idêntico a meu corpo... que eu posso logicamente existir sem corpo. (Danto, $2006: 138)^{1}$

Refletindo sobre as diferentes representações do corpo na tradição da filosofia e da arte, Arthur Danto sublinha a evidente implicação a ser extraída do pensamento cartesiano: é que a distinção entre corpo e alma fundamenta a afirmação da imortalidade da alma $^{2}$. A posição dos filósofos, que Descartes foi aqui chamado a representar, não encontrará, porém, segundo Danto, eco na religião ou na arte. À religião do Deus feito homem importaria naturalmente a carne - já que também a ela é prometida a ressureição, no último dia; quanto à tradição da «arte ocidental», ali se manifestariam «estados interiores universais» que os corpos exprimiriam de forma clara para «nós», diz o autor. É por oposição a essas duas tradições que se ergueria o corpo de que falam os filósofos que de fato foi, sucessivamente, e conforme os modelos disponíveis, comparado a um relógio, um autômato, uma máquina, um computador... Eis assim que filosofia, aqui estritamente aproximada da ciência, seria como um contraponto elucidativo da arte: enquanto o conhecimento sobre o corpo evolui, as novas teorias sempre tornando ultrapassadas as anteriores (a começar, ao que parece, pela reflexão de Aristóteles), aquilo que a arte dá a ver - a experiência do ser encarnado em que nos constituímos, capaz de pensar sobre sua condição incorporada - isto, sustenta Danto, não mudou ao longo do tempo. 
Para o amante da «arte ocidental», estas palavras talvez pareçam consoladoras excessivamente consoladoras, pode-se no entanto pensar. Elas têm o condão de nos assegurar que a arte jamais repeliu a condição corpórea que partilhamos com todos os humanos de todas as épocas mas, ao contrário, a esposou, a investiu e dela serviu-se para realizar este feito estupeficante de conciliar o visível e o invisível, o revelado e o oculto. Toda a questão torna-se, então, de saber se o corpo da arte é, de fato, nosso corpo, entender como se comporta o corpo $n a$ arte, isto é, o corpo daqueles que fazem e são feitos na prática artística.

Assim, é perfeitamente possível afirmar - ainda que não sem certo exagero - que a tradição artística ocidental ter-se-ia abstido de todos os preconceitos que pesaram sobre a materialidade, sobre a aparência, sobre o corpóreo - et pour cause! Muito mais difícil seria implicar daí algum tipo de influência sobre a forma como os humanos, estes seres encarnados, passaram a pensar seus próprios corpos, sobretudo a partir da Modernidade. Neste terreno, por pouco que insistamos em levar às últimas consequências os limites dessa dicotomia entre arte e filosofia, a vitória da última é esmagadora. Pois, muito embora possamos imaginar, com o autor, que Aristóteles teria reconhecido na tela de Poussin, tanto quanto nas obras do período azul de Picasso, a mesma humanidade sobre a qual refletira, o próprio Danto é obrigado a reconhecer que ele teria muito maior dificuldade em significar as produções da fase cubista do pintor: ora, não seria esta, justamente, a marca de uma ruptura que já não consegue se dizer na «linguagem universal» que a tradição ocidental cuidadosamente elaborou? Novas rupturas, novas linguagens tornam o horizonte menos previsível, as dicotomias mais incômodas: interior e exterior, aparência e essência, corpo e alma...

Diz-se que foram os Antigos que trouxeram ao mundo a maior parte dessas divisões que até hoje parecem nos assombrar. Mas, como soe acontecer com as generalizações - sobretudo no que se refere a uma época que, afastada de nós, só por efeito dessa perspectiva nos parece homogênea e reduzida - isso é apenas uma meia verdade. Outras meias verdades poderiam ser igualmente produzidas por aquele que supusesse - o que não ocorre a Danto fazer - que os dogmas cristãos da encarnação divina e da ressureição da carne teriam feito reconciliarem-se de forma inequívoca e de uma vez 
por todas, na tradição, a dimensão interior onde reina a alma e a dimensão exterior onde a carne é soberana. Contudo, se o que nos interessa é menos a consideração do espaços de exceção que a cultura ocidental reservou para a experiência corpórea do que a produção de instrumentos que, municiando-nos para a crítica das representações antropológicas longamente dominantes na sociedade, nos permitam ir além dessas clivagens, então a Antiguidade pode se revelar um terreno, que, por razões opostas as mencionadas acima, mostra-se igualmente fértil.

Nomeei assim, especialmente, o famoso Perí psychés, de Aristóteles - que, entre os latinos, foi chamado de De Anima; e isso porque, ao opor-se ao dualismo platônico, o texto aristotélico apresenta-se como uma das primeiras e até hoje mais importantes contribuições para uma teoria da unidade corpo-alma - e, assim, para que possamos tomar alguma distância em relação à dualidade que se enraíza na história do pensamento pelos aportes da espiritualidade cristã e que se renova na Modernidade em virtude de seu culto da razão: aquela pela qual a «alma» define a incorporeidade própria às essências, por oposição às armadilhas da experiência própria aos sentidos.

É claro que, ao longo de um percurso que vai da anima cristã, sede da conscientia, ao esprit e deste à res cogitans cartesiana, ao self lockiano, à subjetividade transcendental kantiana, a noção de «alma» perdeu o cunho essencialista e inefável que a definira na tradição religiosa, tão estrangeira à psique grega ${ }^{3}$; mas ela ainda mantém como herança desses primórdios a índole intimista, a desconfiança em relação à experiência pura dos sentidos, a relação privilegiada com o saber. Mas, se o racionalismo que impera na tradição filosófica do Ocidente despreza a arte, seria resposta suficiente que a arte despreze, por sua vez, o pensamento, buscando no corpo a experiência direta da sensibilidade e do sentido humanos?

Sem dúvida, foi exatamente a predominância da busca incessante pelo «verdadeiro» saber, pela experiência segura e não menos direta da razão que, como observa Richard Bodeüs (1993, p. 25), desde sempre instalou o problema da alma, do espírito, do pensamento, da consciência - enfim, da instância associada à própria identidade humana, por oposição aos animais e às coisas justamente ditas «inanimadas», 
em uma reflexão de ordem metafísica. Assim, a dualidade corpo-alma nada mais é senão o corolário, o prolongamento de uma dualidade entre mundo-sujeito - esta mesma que Merleau-Ponty pretendeu combater, e que denominou de «estrabismo da ontologia ocidental» (1964, p. 271). Mas como não buscar o outro extremo, desprezando o cuidado com a reflexão e pensamento? O que afinal podem ter em comum a arte conceitual e a exigência de uma experiência direta com a matéria? Pode o corpo pensar? Pode a psique se fazer encarnada (Freud: 1985, p. 288) ${ }^{4}$ ?

\section{Aristóteles e o composto humano}

As questões assim colocadas só fazem ressaltar a novidade da elaboração aristotélica que, para começar, vai estabelecer o Perí psychés como um tratado natural: pois, para Aristóteles, o ser é, primeiramente, natureza - phýsis, isto é, impulso endógeno, crescimento espontâneo - em uma palavra, movimento (Fis, II, 192 b 8)5 ${ }^{5}$. Assim, longe de ser considerada como instância extramundana e metafísica, a psique, «anima», é definida como princípio interno comum a todos os viventes naturais, isto é, a todos os seres que podem ser ditos físicos: animais e vegetais, que conhecem nascimento, crescimento e morte, que se mantêm em vida e se reproduzem. Anima é, pois, princípio de vida que os humanos compartilham com tudo que é submetido a um movimento que vem da natureza.

E, no centro do tratado, Aristóteles apresenta aquela que ficou conhecida como a teoria hilemorfista: contrariando frontalmente o pensamento platônico, ele propõe a indissociabilidade da hulé, a matéria, e da morphé, a forma, a essência, o sentido - uma teoria, enfim, da unidade do corpo e da alma. Ao fazê-lo, Aristóteles inaugura uma via para a reflexão que não foi ainda suficientemente explorada por aqueles que se interessam pelas coisas humanas.

Porque não se trata de distinguir a permanência como verdadeira existência e a mudança como menos-ser, a interrogação sobre a existência - a ontologia aristotélica começa pela questão: o que é próprio do ser que tem movimento próprio? Pois tudo está 
sujeito ao movimento, afora as coisas que são eternas e imutáveis - mas esta questão Aristóteles não pretende tratar aqui. Há, porém, uma diferença entre o que se movimenta por ação de outro e o que é capaz de movimentar-se a si mesmo - o semovente. Assim, o animado e o inanimado correspondem, em Aristóteles, à diferença entre aos seres dotados de psique, empsuchoi, e aqueles que não possuem psique. Mas, qual é a natureza desta distinção entre o animado e o inanimado? É a esta interrogação que o Tratado da Alma, o Peri Psichès, se dedica. O que aparece desde aqui já evidente é que Aristóteles se recusa a estudar a alma como uma realidade em separado da matéria, do corpo sem o qual esta alma não existe.

Contudo, no tratado, matéria e forma (hulé e morphé) são os conceitos que permitem pensar, mais do que o composto humano, a grande questão da criação do novo, ou da emergência do Ser. Como é possível a passagem do nada ao ser? - eis a questão que ocupou a filosofia desde suas origens. No pensamento aristotélico, a matéria é dita um terceiro termo, que permite passar do não-ser, da «privação», à existência. É por isto que a matéria é associada à potência, dunamís. A princípio inacessível, posto que indeterminada, a matéria é a possibilidade aberta que se só se realiza ao se extinguir, sob a forma de uma nova determinação. Para Aristóteles, repita-se, o ser é movimento, viver é atividade. (Id, passim) ${ }^{6} \mathrm{~A}$ alma pode, assim, ser entendida como o «princípio formal, eficiente e final do ser». A alma é o que se faz, no ser, como movimento: a determinação do que é, que o distingue do que não é absolutamente, ou não é aquilo que é próprio deste ser; em outros termos, a capacidade de manter-se como tal, e de se autoformar em direção a um destino.

No pensamento aristotélico, a crítica tanto às concepções materialistas da alma quanto ao idealismo platônico esboçam-se numa teoria em que sensibilidade e intelecção vêm sempre juntas: pois o acesso às realidades sensíveis não se dá sem que se construa um sentido, um conceito, que se forneça uma forma à experiência, assim como o pensamento, o acesso às realidades ditas «inteligíveis» não se faz sem a sensibilidade.

Cognição e sensibilidade são faculdades que definem partes diferentes da psique. Mas isto não significa que se possam pensar estas faculdades ou partes como existindo 
autonomamente. Pelo contrário, Aristóteles considera que «a alma nada sofre e nada faz sem o corpo. Assim, encolerizar-se, transtornar-se, desejar ou, de forma global, sentir.» (403 a 3) Esta unidade entre alma e corpo, antiplatônica e seguramente anticartesiana marca de maneira especial a crítica à noção de ideias desencarnadas:

...sobretudo a operação da inteligência parece ser um fenômeno próprio [da alma]. No entanto, isso sequer poderá ter lugar sem o corpo, se é que se trata de um certo tipo de imaginação (phantasia) ou de algo que não se dá sem imaginação. (...) Todas as afecções da alma estão ligadas ao corpo (ardor, doçura, medo, piedade, audácia, alegria, amar e odiar) porque «esses fenômenos se fazem acompanhar de uma certa afecção do corpo». (403 a 5-10)

O paralelismo (ou uma certa concomitância) das afecções somáticas e das afecções psíquicas não é concebido por Aristóteles em uma perspectiva dualista, como signo de uma influência do corpo sobre a alma, mas em um perspectiva unitária, como o signo de uma associação íntima em que a alma e o corpo constituem dois planos de uma mesma realidade. Desta forma, comenta Cornelius Castoriadis, as afecções da alma são sempre «sentido encarnado» (1987: 335 e seg.)

Mas o que é finalmente, para o filósofo, a alma, psique? A definição clássica produzida no Tratado diz da psique que ela é «realização primeira (enteléquia) de um corpo natural que possui a vida em potência (dunamís)» (412 a 27). Isto é, Aristóteles denomina de «alma» a primeira realização de um corpo que tem (potencialmente) vida. A alma é atividade de um corpo que está em vida. Pois viver é, antes de qualquer outra coisa, poder manter-se em vida, manter este organismo em condições de funcionar. A conservação, ou o crescimento, e a reprodução são as funções elementares do vivente, e correspondem portanto à faculdade dita nutritiva.

Entre os viventes, os animais se distinguem pela faculdade perceptiva, ou sensitiva. Platão dizia que estar em vida é afetar e se deixar afetar, isto é, a vida é definida pela capacidade de agir sobre qualquer coisa ou de sofrer uma ação ${ }^{7}$; Aristóteles vai também definir o animal pela «faculdade sensitiva». O próprio da vida animal é a capacidade de distinguir, de discriminar, no meio em que está, aquilo que, contribuindo para sua existência, lhe é agradável e aquilo que, ao contrário, lhe é doloroso e deve ser evitado (Aristóteles, Ética a Nicômaco, passim). Alguns animais são, assim, dotados de 
uma capacidade motora que lhes permite o simples deslocamento espacial; mas, em muitos casos, produzem-se fenômenos mais complexos, aos quais se dá mais apropriadamente o nome de desejo, que supera a simples capacidade de distinguir entre o que é vantajoso ou desvantajoso para sua sobrevivência. E, para além disto, a capacidade de discriminar o bem e o mal, que faz ser a ética. Alguns animais - entre os quais, de forma muito especial, o humano - possuem ainda uma alma noética, a capacidade de pensar, de produzir sentidos.

Mas o composto humano é ainda dotado de imaginação, dita em grego phantasia. A imaginação não é, no tratado, identificada nem à sensibilidade nem à intelecção: ela, comenta Castoriadis, se encontraria às vezes na sensibilidade, às vezes na intelecção, sem ser nem um nem outro. A imaginação existe como sensível a cada vez que há pensamento. Reciprocamente, a imaginação fornece à sensibilidade o sentido que não é automático, mas criação, a cada vez, do humano que sente. (Castoriadis: 1987, p. 343) Em outras palavras, a fantasia parece fornecer ao inteligível aquilo que lhe escapa, que é a base sensível; e, por outro lado, fornece à sensibilidade a inteligibilidade que não está na matéria, mas na forma que o humano lhe fornece.

O composto humano é capaz, graças à imaginação, de dar sentido, de dar forma àquilo que sente; e para ele o pensamento não se dá apesar do corpo, mas como atividade de um ser encarnado. Assim, o corpo que sente é aquele que, por ser dotado de imaginação, cria sentido para esta experiência; tampouco o pensamento é atividade de um ser desencarnado: é graças à imaginação que as ideias, longe de serem entidades de puros espíritos, são sempre produção de um ser dotado de corpo.

\section{Foucault e o «corpo utópico»}

Mas esta forma de conceber o corpo, como unidade insecável, de que modo ela pode corresponder à experiência que dele fazemos? É finalmente em Foucault que a questão do corpo aparece com toda a ambiguidade que lhe é própria, e que as teses filosóficas nem sempre dão a ver. O corpo como problema, como questão, 
permanentemente colocada, sem que uma solução para o enigma que ele coloca venha a obliterar a interrogação aberta. Corpo como recusa, como sofrimento, limite, gravidade e prisão; mas também - e por que não? - como utopia.

O texto é de uma bela conferência radiofônica realizada em 1966, pelo canal France-Culture (Foucault, 2009, p. 1), comovente pelo tom intimista, autobiográfico e francamente poético que Foucault assume.

Ali, faz-se enfim o relato de um corpo que não é $d a$ filosofia, mas do filósofo: corpo habitado que chama por uma filosofia encarnada em que Danto, é-se tentado a dizer, dificilmente se reconheceria.

O testemunho pessoal retraça as agruras vividas pelo autor: surpreendentemente, o corpo é de saída apresentado como impasse, como estorvo, como o que the permite o deslocamento, mas impede o movimento mais substancial:

...não que eu esteja por ele pregado no chão - já que eu posso não somente mover-me e mexer-me, mas mexe-lo, movê-lo, muda-lo de lugar; no entanto, eis que não posso me deslocar sem ele, não posso deixa-lo lá onde está e ir-me embora, eu, para outro lugar. (Id., p. 2$)^{8}$

Esse primeiro instantâneo do percurso vagaroso que nos propõe Foucault é, pois, do corpo que é o exato oposto de uma utopia: um «lugar absoluto», topos inescapável, «impiedosa topia», diz ele. É de estranhamento e de rejeição que nos fala o filósofo, de uma ferida, desse «rosto magro, ombros arqueados, olhar míope, já sem cabelos, realmente nada bonito» que se apresenta ao espelho como Paul-Michel Foucault - ou, ao menos, como se vê ao espelho Paul-Michel Foucault (id.). Corpo, mal-estar, «jaula que eu não amo», lugar de condenação.

O relato estritamente confessional dessa experiência de ser projetado no que mais se parece uma casca, uma cadeia, uma armadura que dificilmente se carrega, pesada, embaraçosa e inconveniente, leva-nos para nossa própria realidade, mais ou menos assemelhada; mas, em seguida, transporta-nos ainda mais longe, nos faz imaginar a experiência sem memória do recém-nascido que fomos, voltar às marcas da adolescência que deixamos para trás, vislumbrar o declínio que nos aguarda. Experiência que se instala 
nas entranhas da história, no âmago de um sonho que somente à condição de humanidade é dado sonhar:

Imagino, em suma, que é contra ele e para suprimi-lo que se fizeram nascer todas as utopias. O prestígio da utopia, a beleza, o maravilhamento da utopia, a que são devidos? A utopia é um lugar fora de todos os lugares, mas um lugar onde terei um corpo sem corpo, um corpo que será belo, límpido, transparente, luminoso, veloz, colossal em sua potência, infinito em sua duração, liberto invisivel, protegido, sempre transfigurado. Eé bem possivel que a utopia primeira, aquela que é a mais inerradicável no coração dos homens seja precisamente a utopia de um corpo incorpóreo. (id.)

Eis que nos vemos subitamente diante da imortalidade prometida aos heróis e suas pátrias, anunciada pelas religiões, cobiçada pelo projeto político dos impérios: um corpo glorioso, transfigurado, capaz de vencer o tempo e a morte. É assim que Foucault se refere às múmias, às tumbas antigas, mas também às pinturas e esculturas medievais «prolongando na imobilidade uma juventude que não passará jamais», almejando uma eternidade propriamente divina». (id.)

Chega-se por este trajeto tortuoso à «mais obstinada, mais poderosa das utopias pelas quais nós suprimimos a triste topologia do corpo»: trata-se dessa alma longamente concebida na história ocidental que é capaz de transportar para além da opaca materialidade das coisas - de uma alma que «escapa quando durmo, sobrevive quando morro» (id., p. 3).

Contudo, o corpo resiste a estas utopias que pretendem fazê-lo desaparecer, diznos Foucault.

Mas meu corpo, na verdade, não se deixa reduzir assim tão facilmente. Afinal, ele tem seus recursos próprios e fantásticos; possui, ele também, lugares sem lugar e lugares mais profundos, mais obstinados ainda que a alma, que o túmulo, que o encanto dos mágicos. Ele tem seus porões e seus sótãos, ambientes obscuros, espaços luminosos. (id.)

Incompreensível e opaco, o corpo, descobre por fim Foucault, é modelo e origem de todas as utopias pelas quais se pretendia fugir à corporeidade. Pois todas elas dão testemunho da experiência corpórea, e mesmo a tentativa de negá-la acaba por se constituir em sua afirmação. Estonteante reversão, pela qual o texto de Foucault 
subitamente parece atualizar, em termos poéticos e muito intimistas, a teoria hilemorfista do composto humano: «Uma coisa é certa: o corpo humano é o principal ator de todas as utopias.» (Id., p. 4)

\begin{abstract}
Não, na verdade não é preciso nem magia nem maravilha, não é preciso uma alma ou uma morte para que eu seja, a uma só vez, opaco e transparente, visivel e invisivel, vida e coisa : para que eu seja utopia, basta-me ser um corpo. Todas as utopias pelas quais me esquivava de meu corpo, eles tinham simplesmente por modelo e por primeiro ponto de aplicação, elas tinham seu lugar de origem em meu próprio corpo. Eu estava errado quando, há pouco, dizia que as utopias haviam se formado contra o corpo e destinadas a suprimi-lo: elas nasceram do corpo e talvez tenham se voltado em seguida contra ele. Em todo caso, uma coisa é certa, é que meu corpo humano é o ator principal de todas as utopias. (id.)
\end{abstract}

A tatuagem, a maquiagem, a máscara, as vestimentas rituais, sagradas ou profanas dão forma sensível às utopias que marcam o corpo. Pois, em sua materialidade, diz o filósofo, o corpo se faz produto de seus próprios fantasmas: «E, de fato, não seria o corpo do dançarino um corpo dilatado segundo um espaço que lhe é, ao mesmo tempo, interior e exterior?» propõe então Foucault. (id.)

Mais: o corpo é como o «ponto zero» do mundo, em torno do qual tudo se dispõe, para o qual, e somente para o qual há uma direita e uma esquerda, um acima e um abaixo, um próximo e um distante, um antes e um depois... O corpo não está em nenhum lugar, pois ele é «um pequeno núcleo utópico a partir do qual eu sonho, falo, avanço, imagino, percebo as coisas em seu lugar e as nego também, em virtude do indefinido poder das utopias que imagino.» (id., p. 5)

As crianças, observa Foucault, levam muito tempo até tomarem consciência de que têm um corpo - elas têm orifícios, cavidades, membros que só se organizam em um todo na imagem do espelho. E os gregos, acrescenta, não tinham uma palavra para dizer a unidade corpórea, apenas aquela que serve para designar o cadáver. O espelho e o cadáver impedem que o corpo seja pura utopia, ainda que estejam em um lugar inacessível, onde jamais estaremos. 
Mas o texto não se conclui sobre esta nota trágica, pois Foucault se volta para a experiência do amor, que fornece ao corpo sua redenção máxima, sua melhor utopia que está em finalmente fazer-se magnífica topia, fazendo-nos definitivamente presentes.

...sob os dedos do outro, percorrendo-o, todas as partes invisíveis de nosso corpo se põem a existir, contra os lábios do outro os nossos tornam-se sensiveis, diante dos olhos semicerrados nossa face adquire uma certeza, há enfim um olhar para ver nossas pálpebras fechadas. O amor, também ele, como o espelho e como a morte, pacifica a utopia do corpo, faz-na calar-se, a acalma, a encerra como que em uma caixa, fechada e selada. Por isso ele está tão próximo da ilusão do espelho e da ameaça da morte; e se, apesar dessas duas figuras perigosas que o circundam, gostamos tanto de fazer amor, é porque no amor o corpo está aqui.» (id., p. 6)

Então, ao fim deste périplo, não nos encontramos mais avançados do que quando começamos! Pois, ao que parece, a bela unidade do composto, corpo e alma, ainda que verdadeira e atuante, em nada impede, ao contrário, as múltiplas experiências de desencontro que predominam face aos pequenos instantes de inteireza - sofrimento e desprazer definem uma realidade também marcada pela magnífica descoberta da presença inteira do ser... Para Foucault, é finalmente o amor que permite ao humano a experiência plena do composto que nunca deixou de ser, em que pesem todos os momentos em que, deliberada ou inconscientemente, o negou. Que bela lição, que não está inscrita nem na arte, na filosofia, ou na ciência: a presença, o corpo como inteireza, onde encontra-lo, senão no outro? Este é o desafio, esta é a decisão que, finalmente, faz ser a arte, a filosofia e - por que não? - a ciência. 
${ }^{1}$ Eis a íntegra da passagem: «La seule chose que je ne puisse évacuer par la pensée, c'est la pensée. Donc je suis - je ne peux qu'être - ce que Descartes nomme une « chose qui pense ", une res cogitans de par ma nature essentielle. Je peux, assez facilement, penser que je n'ai pas de corps ! Rien ne s'ensuit du fait que je pense qu'il faut un corps pour penser! Je peux nier avoir un corps, et je peux me tromper, mais je ne me tromperai pas de la même façon que lorsque je pense que je ne pense pas. Ainsi se peut-il que j'aie un corps, ou que je n'en aie pas. Mais si je me trompe je dois être un esprit. Sum res cogitans. Le moi qui pense est logiquement distinct du corps. C'est l'opinion de Descartes. Voici l'argument en quelques mots : je ne peux intelligiblement douter de ma propre existence, étant donné que le doute est une forme de pensée et que, si je pense, je suis. En revanche, je peux intelligiblement douter que j'aie un corps. D'où il résulte que je ne suis pas identique à mon corps. D'où il résulte que je peux logiquement exister sans corps.» (Danto: 2006, 138).

${ }^{2}$ De fato, desde pelo menos a escola pitagórica propunha-se a imortalidade da alma e, assim, a distinção entre corpo e alma. Repare-se, porém, que, em Descartes, a afirmação da diferença substancial entre corpo e alma deve se adequar àquela de sua união, misteriosamente realizada pela glândula pineal. (Cf. Descartes, Princípios, I, 60; Meditações, VI, §17-29 e, especialmente, §17, §23-24, §27.)

3 «As Confissões testemunham o outro império, o império cristão, que, no fim da Antiguidade, Santo Agostinho abriu para os século seguintes: o reino da interioridade. A alma representava a essência do homem, mas não eram os horizontes cheios de mistério e de desconhecido da própria interioridade, que não estão menos ocultos para o homem que os horizontes do mundo exterior.» (Arendt: 1997, p. 175)

${ }^{4}$ A psique é extensão, dizia, em nota póstuma, Freud (1985, p. 288).

5 No livro II da Física aristotélica, os seres naturais são apresentados (por oposição aos seres artificiais, para os quais o movimento só ocorre por acidente, causado por um agente exterior que age sobre sua matéria) como comportando neles próprios a causa de seu movimento e repouso (192 b 8) [Observe-se que aqui as citações de obras da Antiguidade seguem as normas universalmente aceitas, mencionando-se as páginas e colunas que constam das edições clássicas. Assim, por exemplo, Física, II, 192 b 8, identifica as referências que permitirão, em qualquer tradução que se escolha, encontrar a passagem mencionada no livro II da Física.]

${ }^{6}$ Mas nem todo movimento é atividade. Aristóteles distingue o movimento local, que é simples transporte ou deslocamento (capacidade motora), da alteração resultante da sensação (capacidade cognitiva) e do crescimento e geração (capacidade nutritiva e reprodutiva). Id., passim.

${ }^{7}$ Platão, Sofista, 247 e.

${ }^{8}$ «Ce lieu que Proust, doucement, anxieusement, vient occuper de nouveau à chacun de ses réveils, à ce lieu-là, dès que j'ai les yeux ouverts, je ne peux plus échapper. Non pas que je sois par lui cloué sur place - puisque après tout je peux non seulement bouger et remuer, mais je peux le remuer, le "bouger", le changer de place - seulement voilà : je ne peux pas me déplacer sans lui ; je ne peux pas le laisser là où il est pour m'en aller, moi, ailleurs. Je peux bien aller au bout du monde, je peux bien me tapir, le matin, sous mes couvertures, me faire aussi petit que je pourrais, je peux bien me laisser fondre au soleil 
sur la plage, il sera toujours là où je suis. il est ici irréparablement, jamais ailleurs.» Id., p. 2. 
Referências bibliográficas

ARENDT, Hannah. O Conceito de amor em Santo Agostinho. Lisboa: Instituto Piaget, 1997, p. 175.

ARISTÓTELES. Ética a Nicômaco. [Éthique a Nicomaque. Paris: Flammarion, 2004, trad. Richard Bodeüs].

ARISTÓTELES. Da Alma. [De l’Âme. Paris: Flammarion, 1993, trad. Richard Bodeüs] BODEÜS, Richard. Présentation de De l'âme. Paris : Flammarion, 1993.

CASTORIADIS, Castoriadis. A Descoberta da imaginação, Encruzilhadas do labirinto

II. Domínios do homem. Rio de Janeiro : Paz e Terra, 1987, p. 343, 335-372.

DANTO, Arthur. Le corps dans la philosophie et l'art. Cités, Paris, PUF, nº 26, p. 138, $2006 / 2$

DESCARTES, René. Meditações, VI, §17-29 e, especialmente, §17, §23-24, §27. [Méditations. Paris: Vrin, 1978]

DESCARTES, René. Princípios de Filosofia, I, 60.

FOUCAULT, Michel. Le corps utopique. Les hétérotopies. Paris: Ed. Lignes, 2009 [https://tinyurl.com/ybkmmoza Acesso em 18/06/2017]

FREUD, Sigmund. Résultats, idées, problèmes. Paris: PUF, 1985, p. 288.

MERLEAU-PONTY, Maurice. Le Visible et l'invisible. Paris: Gallimard, 1964, p. 271.

PLATÃO. Sofista. [Sophiste. Euvres complètes. Paris : Flammarion, 2006, dir. Luc Brisson] 